\title{
Experimental and DFT Investigation on the Corrosion Inhibition of Mild Steel by 1,2,3-Triazolereg Ioisomers in 1M Hydrochloric Acid Solution
}

\author{
H. Rahmani ${ }^{1,2}$, K. Ismaily Alaoui ${ }^{1}$, K.M. Emran ${ }^{3 *}$, A. El Hallaoui ${ }^{2}$, M. Taleb ${ }^{1}$, S. El Hajji ${ }^{2}$, \\ B. Labriti ${ }^{2}$, E. Ech-chihbi ${ }^{1,4}$, B. Hammouti ${ }^{5}$, F. El-Hajjaji ${ }^{1}$ \\ ${ }^{1}$ Laboratory of Engineering, Electrochemistry, Modeling and Environment (LIEME), Faculty of Sciences, \\ University Sidi Mohamed Ben Abdellah, Fez, Morocco \\ ${ }^{2}$ Laboratory of organical Chemistry (LOC), Faculty of sciences, University Sidi Mohamed Ben Abdellah, Fez, \\ Morocco \\ ${ }^{3}$ Department of Chemistry, College of Science, Taibah University, Al-Madinah Al-Monawarah, $\quad$ PO Box4050, \\ Saudi Arabia. \\ ${ }^{4}$ Laboratory of separation processes, Faculty of Science, University Ibn Tofail, Kenitra, Morocco \\ ${ }^{5}$ Laboratory of Applied Analytical Chemistry Materials and Environment (LCAAE), Faculty of sciences, University \\ of Mohammed Premier, Oujda, Morocco \\ *Corresponding authors Emails:kabdalsamad@taibahu.edu.sa,el.hajjajifadoua25@gmail.com
}

\section{Abstract document}

1-[(4-ethyl-2-phenyl-4,5-dihydro-1,3-oxazol-4-yl)methyl]-4-phenyl-1H-1,2,3-triazole (Ph4) and1-[(4ethyl-2-phenyl-4,5-dihydro-1,3-oxazol-4-yl)methyl]-5-phenyl-1H-1,2,3-triazole (Ph5) are new isomers of the triazole derivative family, were synthesized and tested on the corrosion of mild steel in molar hydrochloric acid molar media using weight loss, electrochemical polarization and impedance spectroscopy. Then the experimental results were confirmed by quantum chemical calculations using DFT at B3LYP /6-31G (d,p). The compound Ph4 is the best inhibitor and its inhibitory efficiency increased with increasing concentration and reaching $95 \%$ at $10^{-3} \mathrm{M}$. Polarization curves studies show that both compounds tested are mixed-type inhibitors. Nyquist curves presented a single capacitive loop, their diameter increases progressively with both inhibitors concentration. The change of the substitution phenyl from position 5 to position 4 in the triazole ring increases the inhibitory effect of the triazole compounds. The effect of temperature on the corrosion behavior of iron indicates that the inhibitory efficiency of the two inhibitors decreases with increasing temperature in the range of 308 to 338K. DFT study is in good correlationwith the experimental results.

Keywords: Oxazole -Triazole, Inhibition corrosion, Mild steel, EIS, DFT

\section{Introduction:}

The corrosion is one of the major problems that affect the economy and safety, especially for metals and alloys. Mild steel is widely used in a wide range of industries and machinery. But the corrosion of steel is a fundamental academic and industrial concern which has received considerable attention [1]. Recently, the organic inhibitors were used in many industries process by protecting the materials from deterioration due to corrosion, particularly in an acid medium. 
The organic molecules decrease the corrosion rate in the acidic medium by adsorbing on the surface of the steel [2-3]. These inhibitors contain some heteroatoms such as oxygen, nitrogen, phosphor, sulfur and multiple bonds, it allow an important adsorption on the metal surface [4-5]. New environmental restrictions have resulted in the use of environmentally acceptable substitution compounds (green inhibitors), for instance, the triazole derivatives have been effective as metal corrosion inhibitors in many Corrosive systems [6-7]. Many triazole derivatives containing $\mathrm{N}$ and $\mathrm{O}$ are corrosion inhibitors that are environmentally eco-friendly [8-9]. A series of oxazoline-triazole derivatives were synthesized in the laboratory, for the purpose of investigating their anti-corrosive behavior on mild steel in $1 \mathrm{M} \mathrm{HCl}$.Ansari et al. [10] have reported the inhibitive effect of some Schiff base of pyridyl substituted triazoles SB-1, SB-2 and SB-3 on the corrosion of mild steel in hydrochloric medium $1 \mathrm{M} \mathrm{HCl}$, they conclude that all the molecules had showed a good inhibition with a slight difference in the efficiencies, this result is due to their chemical structures and the presence of a various active sites that provide a good adsorption on the metal surface. Similarly, Rugmini et al. [11] had investigated the function of triazole based Schiff base 1,2,4-triazole based Schiff base on the corrosion of the mild steel in $0.5 \mathrm{M} \mathrm{HCl}$, they had explained it efficiency by the presence of nitrogen, oxygen, the multiple bonds and the aromatic rings.

The present work aims to investigate the corrosion inhibition of two isomers 1-[(4-ethyl-2-phenyl4,5-dihydro-1,3-oxazol-4-yl)methyl]-5-phenyl-1H-1,2,3-triazole Ph5 and 1-[(4-ethyl-2-phenyl4,5-dihydro-1,3-oxazol-4-yl)methyl]-4-phenyl-1H-1,2,3-triazole $\mathbf{P h 4}$ on the mild steel as the studied metal in a hydrochloric acid medium $1 \mathrm{M} \mathrm{HCl}$ by weight loss, Tafel polarization and electrochemical impedance spectroscopy (EIS) techniques. The experimental results are complemented with theoretical DFT quantum chemical calculations.

\section{Experimentaldetails}

\subsection{Material preparation and inhibitors}

The molecular formula of the examined inhibitor is shown in Table1.The inhibitors were added to freshly prepared $1 \mathrm{M} \mathrm{HCl}$ in the concentrationrange of $10^{-6}$ to $10^{-3} \mathrm{M}$. The aggressive solution was prepared by dilution of analytical grade $37 \% \mathrm{HCl}$ with distilled water. 
Table 1

Names and chemical structures of the organic compounds investigated.

\begin{tabular}{cc}
\hline Abbreviation & 1-[(4-ethyl-2-phenyl-4,5-dihydro-1,3-oxazol-4-yl)methyl]-4-phenyl-1H-1,2,3- \\
$\mathbf{P h} 4$ & 1-[(4-ethyl-2-phenyl-4,5-dihydro-1,3-oxazol-4-yl)methyl]-5-phenyl-1H-1,2,3- \\
triazole
\end{tabular}

The steel used in this study is a mild steel with a chemical composition (wt. \%): $0.21 \% \mathrm{C}, 0.38 \%$ Si, $0.05 \% \mathrm{Mn}, 0.05 \% \mathrm{~S}, 0.09 \% \mathrm{P}, 0.01 \% \mathrm{Al}$ and balance Fe wasused. The steel specimens were pre-treated prior to the experiments by grinding with different grades of emery papers with 220 up to 1500 , washed with distilled water, cleaned with acetone, washed again with distilled water and then dried at room temperature before use.

\subsection{General procedure for the Synthesis}

The action of phenylacetylene on 4- (azidomethyl) -4-ethyl-2-phenyl-4,5-dihydro-1,3-oxazole at $120{ }^{\circ} \mathrm{C}$, in a small amount of toluene with stirring for $48 \mathrm{~h}$ yields two position isomers "Regioisomers" which are separated by chromatography on silica gel column[12].<smiles>CCC1(CN[C+]c2ccccc2)COC(c2ccccc2)=N1</smiles>

Ph5

Ph4

1H-NMR (CDCl3, $\boldsymbol{\delta}$ ppm): 1.01 (t, 3H, CH2 $\underline{\mathrm{CH} 3}$ ); 1.76 (q, 2H, $\left.\underline{\mathrm{CH}_{2}} \mathrm{CH}_{3}\right) ; 4.22,4.41$ (AB, $2 \mathrm{H}, J$ $=9.16 \mathrm{~Hz}, \mathrm{CH} 2 \mathrm{O}), 4.54$ and $4.64(\mathrm{AB}, 2 \mathrm{H}, J=13.97 \mathrm{~Hz}, \mathrm{CH} 2 \mathrm{~N}), 7.25-7.91$ (m, 10 Harom), 7.86 (s, 1Htriazole). 


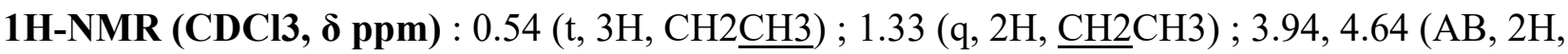
$\left.J=9.16 \mathrm{~Hz}, \mathrm{CH}_{2} \mathrm{O}\right), 4.35(\mathrm{~S}, 2 \mathrm{H}, \mathrm{CH} 2 \mathrm{~N}), 6.85-6.55$ (m, 10 Harom), 7.35 (s, 1Htriazole).

\subsection{Electrochemical techniques}

Electrochemical measurements were performed using a three-electrode cell. A pure mild steel sample such as electrode, platinum wire as counter electrode and saturated calomel electrode (SCE) as electrode reference were used at room temperature. The working electrode was immersed in the test solution $(1 \mathrm{M} \mathrm{HCl}$ without or with the inhibitors) for $0.5 \mathrm{~h}$ until a stable potential was reached before the measurement. The polarization experiments of the potentiodynamic curves were carried out by the Potentiostat Radiometer-analytical PGZ 100 and controlled with the analysis software Voltamaster 4. The soft-steel electrode was kept open circuit conditions (corrosion potential, $E_{\text {corr }}$ ) and then pre-polarized at $-800 \mathrm{mV}$ for $10 \mathrm{~min}$. After this analysis, the potential was scanned at anode potentials. The anodic and cathodic polarization curves were recorded at a scanning speed of $1 \mathrm{mVs}^{-1}$. The EIS study were performed by using Voltalab PGZ 100 [13], with a small amplitude A.C. signal (10 mV rms) over a frequency range between $100 \mathrm{kHz}$ to $10 \mathrm{mHz}$ at $298 \mathrm{~K}$ with five points per decade. The computer programs automatically control the measurements [14-16].

\subsection{Gravimetric measurements}

The gravimetric measurements were carried out in a cell equipped with a thermostatic controlled condenser. The volume of the solution was $5 \mathrm{ml}$. The mild steel specimens used have a rectangular shape (length $=2 \mathrm{~cm}$, width $=1 \mathrm{~cm}$, thickness $=0.2 \mathrm{~cm}$ ) are immersed vertically for 6 hours in the corrosive solution in the absence and the presence of inhibitors. At the end of the tests the specimens were washed with distilled water then weighed [17-18].

\subsection{Theoretical study}

Theoretical calculations were carriedusing density functional theory (DFT) by the hybrid functional and Lee-Yang-Paar correlation functional B3LYP/6-31G $(\mathrm{d}, \mathrm{p})$ basis set for all atoms with the Gaussian 09W program, the symmetry constraints were neglected for full geometry optimizations. The optimized molecular structures and some electronic properties such as energy of the highest occupied molecular orbital (Еномо), energy of the lowest unoccupied molecular orbital (ELUMo), and energy gap ( $\triangle \mathrm{E})$ between LUMO and HOMO surfaces were calculated and discussed [19]. 


\section{Results and discussion}

\subsection{Potentiodynamic Polarization Studies}

Polarization measurements were carried out in order to acquisition of knowledge on the anodic and cathodic kinetics reactions. Potentiodynamic polarization curves for mild steel with different concentrations of $\mathrm{Ph} 4$ and $\mathrm{Ph} 5$ are presented in Fig.1.
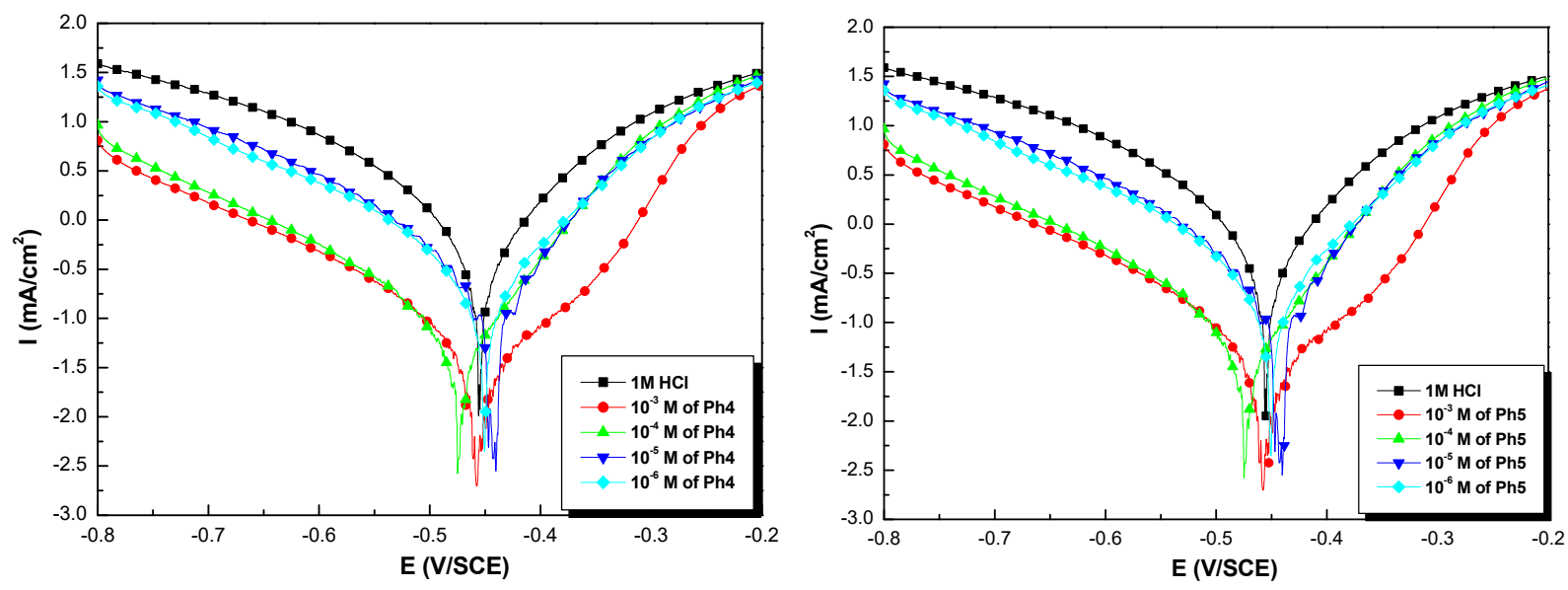

Figure 1. Potentiodynamic polarization plots for mild steel in $1 \mathrm{M} \mathrm{HCl}$ containing different concentrations of $\mathrm{Ph} 4$ and $\mathrm{Ph} 5$.

Both anodic and cathodic curves of current potential are extrapolated to their intersection at a time when corrosion [20-21]. Table 2 shows the electrochemical parameters such as the current density $i_{\text {corr, }}$ corrosion potential $E_{\text {corr }}$ and cathodic tafel slops $\beta_{c}$ obtained from Tafel plots for the mild steel in the hydrochloric acid solution. Where the inhibition efficiency $\operatorname{IE}_{\mathrm{pp}}(\%)$ was calculated by the following equation

The Ecorr values are calculated by using the next Eq.(1) [22-23].

$I E_{P P} \%=\frac{i_{c o r r}-i_{c o r r}^{\prime}}{i_{c o r r}} * 100$

where $i_{\text {corr }}$ and $i$ ' corr represent the corrosion current densities of mild steel in the absence and the presence Metals of inhibitor ( $\mathrm{Ph} 4$ or $\mathrm{Ph} 5)$, respectively.

Compared with the blank solution, the cathodic currents were significantly decreased with the presence of studied compounds made $E_{\text {corr }}$ shifted towards negative potentials (Fig. 1), which suggested that $\mathrm{Ph} 4$ and $\mathrm{Ph} 5$ greatly reduced the hydrogen evolution reaction. 


\section{Table 2}

Polarization parameters and the inhibition efficiency of mild steel corrosion in $1 \mathrm{M} \mathrm{HCl} \mathrm{containing} \mathrm{different}$ concentrations of $\mathrm{Ph} 4$ and $\mathrm{Ph} 5$ at $298 \mathrm{~K}$.

\begin{tabular}{|c|c|c|c|c|c|}
\hline Medium & $\begin{array}{c}\text { Concentration } \\
\text { (M) }\end{array}$ & $\begin{array}{c}\mathbf{E}_{\text {corr }} \\
(\mathrm{mV} / \mathrm{SCE})\end{array}$ & $\begin{array}{c}\mathbf{i}_{\text {corr }} \\
\left(\mu \mathrm{A} \cdot \mathbf{c m}^{-2}\right)\end{array}$ & $\begin{array}{c}-\beta_{\mathrm{c}} \\
\left(\mathrm{mV} \cdot \mathrm{dec}^{-1}\right)\end{array}$ & $\begin{array}{l}I E_{p p} \\
(\%)\end{array}$ \\
\hline $1 \mathrm{M} \mathrm{HCl}$ & 0 & -456 & 1072 & 176 & \\
\hline \multirow{4}{*}{ Ph4 } & $10^{-6}$ & -484 & 337 & 173 & 68 \\
\hline & $10^{-5}$ & -449 & 334 & 175 & 67 \\
\hline & $10^{-4}$ & -467 & 66 & 173 & 94 \\
\hline & $10^{-3}$ & -461 & 44 & 184 & 96 \\
\hline \multirow{4}{*}{ Ph5 } & $10^{-6}$ & -450 & 382 & 191 & 64 \\
\hline & $10^{-5}$ & -442 & 289 & 160 & 73 \\
\hline & $10^{-4}$ & -475 & 103 & 173 & 90 \\
\hline & $10^{-3}$ & -457 & 75 & 180 & 93 \\
\hline
\end{tabular}

The experimental values show that the current density of corrosion $i_{\text {corr }}$ values decrease progressively by increasing the concentration of both $\mathrm{Ph} 4$ and $\mathrm{Ph} 5$ molecules. Furthermore, the inhibition efficiency increases with the increase of the concentration of each inhibitor. Current densities in the addition of the inhibitor indicate an anodic dissolution delay of the mild steel as well as reduction of hydrogen ions. A change in the Ecorr value is noticed in the presence of $\mathrm{Ph} 4$ and $\mathrm{Ph} 5$. According to Ferreira et al. [24], if the displacement $\mathrm{E}_{\text {corr }}>85 \mathrm{mV}$, the inhibitor acts as a cathodic or anodic inhibitor, if the displacement $\mathrm{E}_{\text {corr }}<85 \mathrm{mV}$, the inhibitor is considered as mixed type inhibitor [25]. In the present study, in Fig.1, the maximum shifting in the $E_{\text {corr }}$ value compared to the blank is $28 \mathrm{mV}$ for $\mathrm{Ph} 4$ and 19 for $\mathrm{Ph} 5$, indicating that the inhibitors studied are a mixed inhibitor.

\subsection{Electrochemical Impedance Spectroscopy (EIS)}

The study of the Nyquist plots for various concentrations has been studied in order to complete comprehend the corrosion and inhibition mechanisms of mild steel in hydrochloric medium. Nyquist diagrams of steel immersed in solutions before and after the addition of different concentrations of $\mathrm{Ph} 4$ and $\mathrm{Ph} 5$ inhibitors at $298 \mathrm{~K}$ are given in Fig. 2. The impedance spectra are consisted of capacitive loops indicates that a charge transfer process mainly controls the corrosion of mild steel [26]. The diameter of the capacitive loop is enlarging gradually with increasing concentrations of the both inhibitors indicating that the charge transfer resistance is increasedand the adsorbed inhibitor forms a more compact monolayer on metal surface with an increasing amount of inhibitor [27]. 

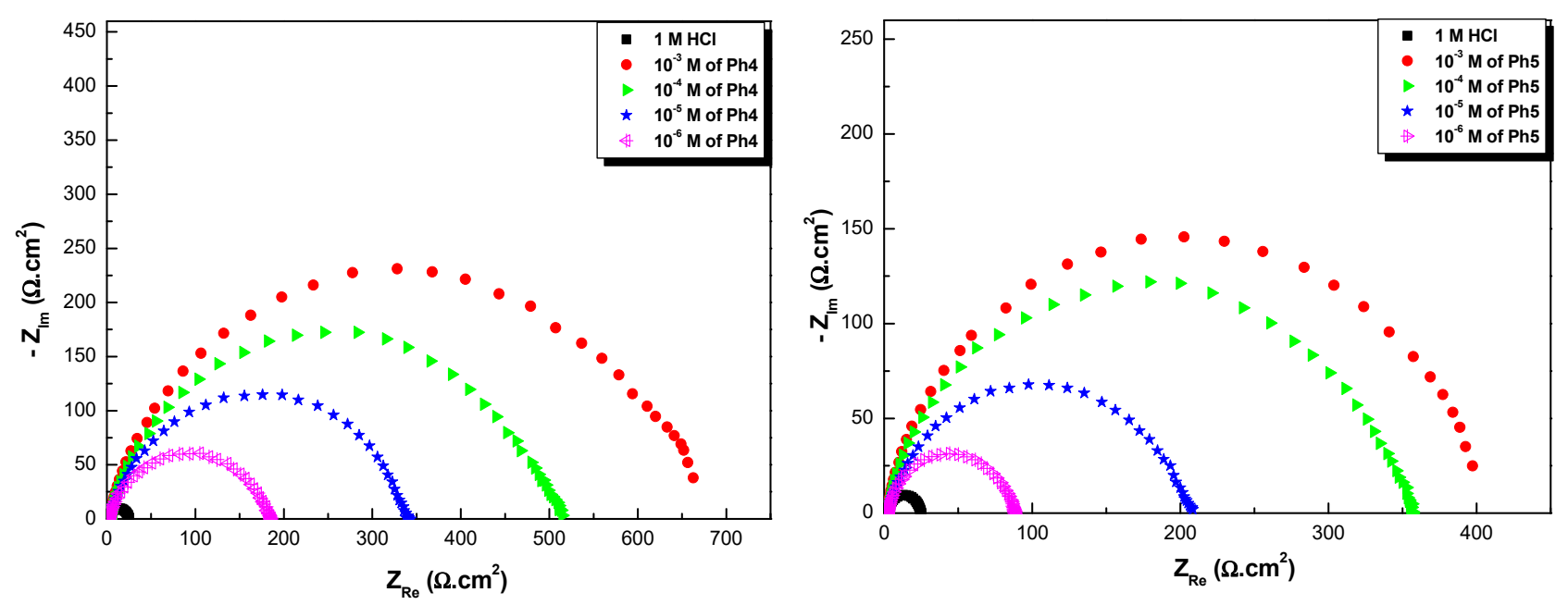

Figure 2.Nyquist diagrams for mild steel in $1 \mathrm{M} \mathrm{HCl}$ containing different concentrations of $\mathrm{Ph} 4$ and $\mathrm{Ph} 5$.

The representative equivalent electrical circuit, in the case of adsorption of the compounds $\mathrm{Ph} 4$ and $\mathrm{Ph} 5$ is shown in Fig.3. This circuit consists of the resistor Electrolyte $\left(\mathrm{R}_{\mathrm{s}}\right)$, a constant phase element (CPE), used in place of the capacitance of the Double layer $\left(\mathrm{C}_{\mathrm{dl}}\right)$ to account for surface inhomogeneities [28-29], positioned in Parallel to a charge transfer resistor ( $\mathrm{R}_{\mathrm{ct}}$ ).

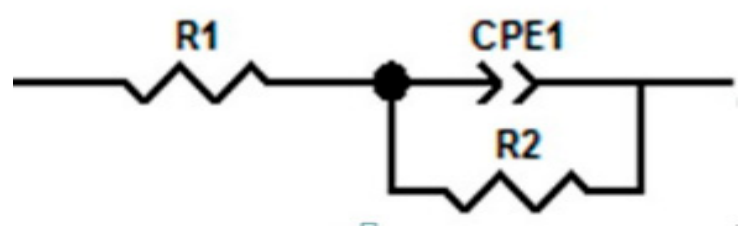

Figure 3. Electrical equivalent circuit used to fit the EIS data of the interface mild steel/1M HCl solution without and with investigated inhibitors.

The charge transfer resistance $\left(\mathrm{R}_{\mathrm{ct}}\right)$ values were calculated from the difference in impedance at low and high frequencies [30]. The efficiency of the corrosion inhibition (IERct\%) were calculated using Eq.(2):

$I E_{R_{c t}} \%=\frac{R_{c t}-R_{c t}^{\prime}}{R_{c t}}$

where $R_{c t}$ and $R_{c t}^{\prime}$ are the charge transfer resistance values without and with the both studied inhibitors. 


\section{Table 3}

Characteristic parameters evaluated from the impedance diagram in the absence and the presence of $\mathrm{Ph} 4$ and $\mathrm{Ph} 5$ in $1 \mathrm{M} \mathrm{HCl}$.

\begin{tabular}{|c|c|c|c|c|c|}
\hline Medium & $\begin{array}{c}\text { Concentration } \\
\text { (M) }\end{array}$ & $\begin{array}{c}\text { Rs } \\
\left(\Omega . \mathrm{cm}^{2}\right)\end{array}$ & $\begin{array}{c}\mathbf{R}_{\mathrm{ct}} \\
\left(\Omega . \mathbf{c m}^{2}\right)\end{array}$ & $\begin{array}{c}C_{d l} \\
\left(\mu \mathrm{F} \cdot \mathrm{cm}^{-2}\right)\end{array}$ & $\begin{array}{c}\text { IE }_{\text {Rct }} \\
\%\end{array}$ \\
\hline 1M HCl & 0 & 2.1 & 23 & 152 & --- \\
\hline \multirow{4}{*}{ Ph4 } & $10^{-6}$ & 1.2 & 186 & 93 & 88 \\
\hline & $10^{-5}$ & 2.1 & 336 & 72 & 93 \\
\hline & $10^{-4}$ & 1.5 & 499 & 54 & 95 \\
\hline & $10^{-3}$ & 0.8 & 669 & 53 & 97 \\
\hline \multirow{4}{*}{ Ph5 } & $10^{-6}$ & 1.8 & 87 & 130 & 74 \\
\hline & $10^{-5}$ & 1.2 & 209 & 95 & 89 \\
\hline & $10^{-4}$ & 0.1 & 347 & 35 & 93 \\
\hline & $10^{-3}$ & 1.1 & 404 & 33 & 94 \\
\hline
\end{tabular}

From the calculated parameters in the Table 3, it can be concluded that the transfer of charge resistance values increases with an increase in inhibitor concentration, this result indicates an increase the efficiency of the corrosion inhibition. The EIS diagrams obtained in with and without the inhibitors are almost have a half circle forms Fig. 3. The transfer of charge process, according to this result, controls the corrosion of mild steel. The $\mathrm{C}_{\mathrm{dl}}$ capacity values decrease by increasing the concentration for each inhibitor, it could be due to the molecules adsorption on the mild steel surface generating an insoluble barrier film from the acid solution [31-33]. All these compounds improve the transfer resistance loading $\mathrm{R}_{\mathrm{ct}}$ and show a decrease in the double layer capacity $\mathrm{C}_{\mathrm{dl}}$ in acid medium.

The results obtained for every concentration of $\mathrm{Ph} 4$ and $\mathrm{Ph} 5$ studied show that these molecules reduce the corrosion rate of the metal surface in $1 \mathrm{M} \mathrm{HCl}$. The values of the corrosion rate of mild steel decrease when the concentration of the inhibitor increases. Moreover, the efficiency of these inhibitors is greater for $\mathrm{Ph} 4$ than for $\mathrm{Ph} 5$ [34].

\subsection{Effect of temperature}

Temperature is among the important factor that can change the behavior of a material in a corrosive environment. It can modify the inhibitor-metal interaction in a given medium. Inhibitors have the role of protecting the latter against acid attacks. These studies revealed a decrease in powerinhibitor by increasing the temperature. It has been proved that with the increase in temperature, few molecules retain their powers of inhibition [35]. The temperature study was performed at different temperatures (between $308 \mathrm{~K}$ to $338 \mathrm{~K}$ ) by the weight loss technique in the absence and presence of the optimal concentration equal $10^{-3} \mathrm{M}$ for both compounds in $1 \mathrm{M} \mathrm{HCl}$ medium. The obtained results are calculated and listed in Table 4. 


\section{Table 4}

Corrosion parameters values for mild steel in $1 \mathrm{M} \mathrm{HCl}$ without and with different inhibitors at $10-{ }^{3} \mathrm{M}$ after $2 \mathrm{~h}$ immersion period.

\begin{tabular}{|c|c|c|c|c|c|c|}
\hline \multirow[b]{2}{*}{ Temperatur } & \multicolumn{2}{|c|}{ 1M HCl } & \multicolumn{2}{|c|}{ Ph4 } & \multicolumn{2}{|c|}{ Ph5 } \\
\hline & $\begin{array}{c}W_{\text {corr }} \\
\left(\mathrm{mg} \cdot \mathrm{cm}^{-2} h^{-1}\right)\end{array}$ & $\mathrm{IE} \%$ & $\begin{array}{c}\mathrm{W}_{\text {corr }} \\
\left(\mathrm{mg} \cdot \mathrm{cm}^{-2} \mathrm{~h}^{-1}\right)\end{array}$ & $\mathrm{IE} \%$ & $\begin{array}{c}\mathrm{W}_{\text {corr }} \\
\left(\mathrm{mg} \cdot \mathrm{cm}^{-2} \mathrm{~h}^{-1}\right)\end{array}$ & $\mathrm{IE} \%$ \\
\hline 308 & 0,852 & - & 0,039 & 95 & 0,059 & 93 \\
\hline 318 & 1,690 & - & 0,090 & 95 & 0,130 & 92 \\
\hline 328 & 3,860 & - & 0,320 & 92 & 0,424 & 89 \\
\hline 338 & 6,154 & - & 0,603 & 90 & 1,070 & 82 \\
\hline
\end{tabular}

The corrosion rates increase with temperature, which implies the reduction of the inhibitory efficiency. The rate of corrosion increases markedly with increasing temperature due to the higher dissolution of mild steel at a higher temperature which could cause desorption of the studied inhibitors from the mild steel surface [36-37].

\subsection{Thermodynamic parameters of the activation corrosion process}

For more details on the corrosion process, activation kinetic parameters, for example, the activation energy $\left(E_{a}\right)$, the enthalpy $\left(\Delta H^{*}\right)$ and the entropy $\left(\Delta \mathrm{S}^{*}\right)$ were calculated according to The Arrhenius law, Eq.(3), and the alternative formula of the following Arrhenius, Eq.(4) [38]:

$W_{\text {corr }}=A \exp \left(-\frac{E_{a}}{R T}\right)$

$W_{\text {corr }}=\frac{R T}{N h} \exp \left(\frac{\Delta S^{*}}{R}\right) \exp \left(\frac{\Delta H^{*}}{R T}\right)$

where $W_{\text {corr }}$ is the corrosion rate, Ea is the apparent activation energy, $\mathrm{R}$ is the gas constant, $\mathrm{A}$ is the Arrhenius pre-exponential factor, $\mathrm{N}$ is Avogadro's number, $\mathrm{h}$ is Plank's constant, $\Delta \mathrm{S}^{*}$ is the entropy of activation and $\Delta H^{*}$ is the enthalpy of activation.

Plotting (Ln $W_{\text {corr }}$ ) versus 1/T gives straight lines as revealed from Fig.4. 


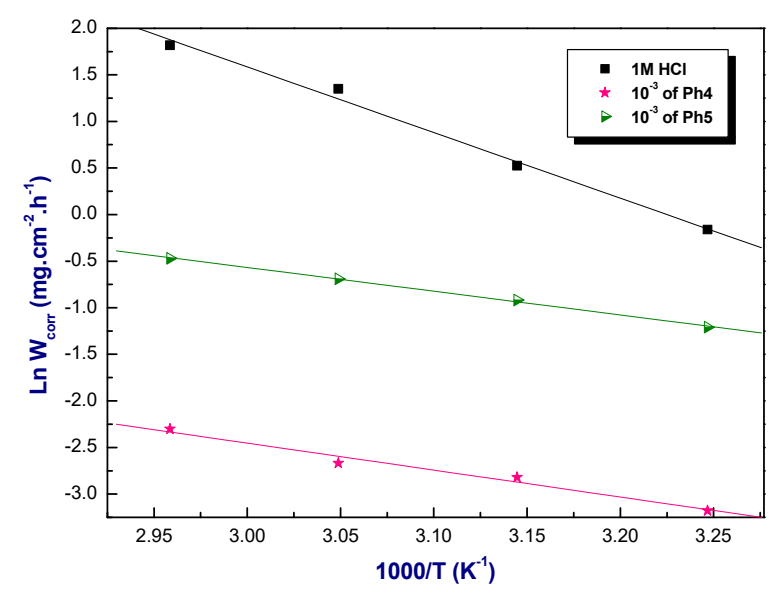

Figure 4. Arrhenius plots for mild steel in $1 \mathrm{M} \mathrm{HCl}$ in absence and in presence of $10^{-3} \mathrm{M}$ of $\mathrm{Ph} 4$ and Ph5.

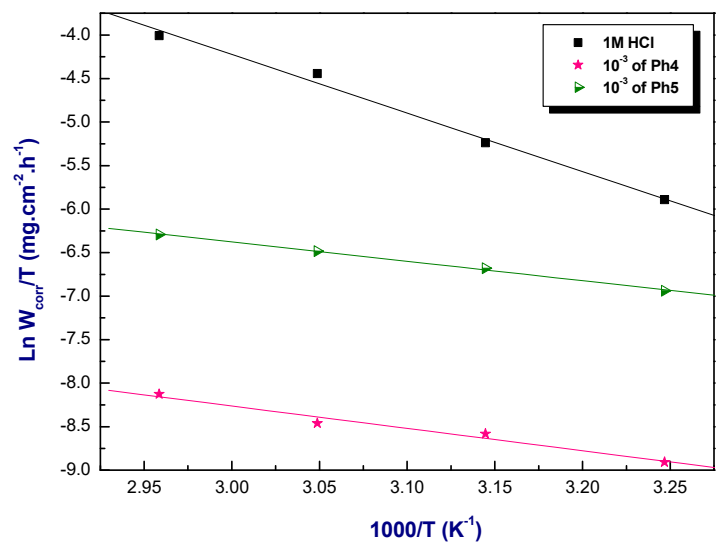

Figure 5. Transition-state plots for mild steel in $1 \mathrm{M} \mathrm{HCl}$ in absence and presence of $10^{-3} \mathrm{M}$ of $\mathrm{Ph} 4$ and $\mathrm{Ph} 5$.

\section{Table 5}

Activation parameters for mild steel in $1 \mathrm{M} \mathrm{HCl}$ in the absence and in the presence of $\mathrm{Ph} 4$ and $\mathrm{Ph} 5$ at optimal concentration $10^{-3} \mathrm{M}$ at different temperatures.

\begin{tabular}{|c|c|c|c|}
\hline Medium & $\mathrm{Ea}\left(\mathrm{KJ}_{\mathrm{mol}}{ }^{-1}\right)$ & $\Delta \mathbf{H} *\left(\mathrm{KJ}_{\mathrm{mol}}{ }^{-1}\right)$ & $\Delta S^{*}\left(\mathrm{KJ} \cdot \mathrm{mol}^{-1} \cdot \mathrm{K}^{-1}\right)$ \\
\hline 1M HCl & 58.580 & 55.899 & -64.958 \\
\hline Ph4 & 82.047 & 79.360 & -14.705 \\
\hline Ph5 & 85.374 & 82.693 & -1.0123 \\
\hline
\end{tabular}


The values of both the activation energy $\mathrm{E}_{\mathrm{a}}$ are lower in the presence of inhibitor suggesting the increase of the barrier's energy along the process of corrosion, therefore the dissolution of the metal surface sites will be more difficult [39-40].The positive sign of $\Delta H^{*}$ has been attributed to the endothermic nature of the mild steel dissolution process [41]. The increase of $\Delta \mathrm{S}^{*}$ is usually interpreted as an increase in disorder as the reactants are converted to theactivated complexes [42]. 


\subsection{Adsorption isotherm}

The adsorption process of $\mathrm{Ph} 4$ and $\mathrm{Ph} 5$ was subsequently evaluated to get a better idea of its inhibitory mechanism. Surface coverage values $(\theta)$ at various concentrations were provisionally adapted to Langmuir Isotherm, which is interpreted by Eq.(5) [43]:

$\frac{C_{i n h}}{\theta}=\frac{1}{K}+C_{i n h}$

where $\theta$ is the surface coverage degree as a function of the inhibitor concentration, $\mathrm{K}_{\mathrm{ads}}$ is the equilibrium constant of the adsorption process and $\mathrm{C}_{\mathrm{inh}}$. is the inhibitor concentration.

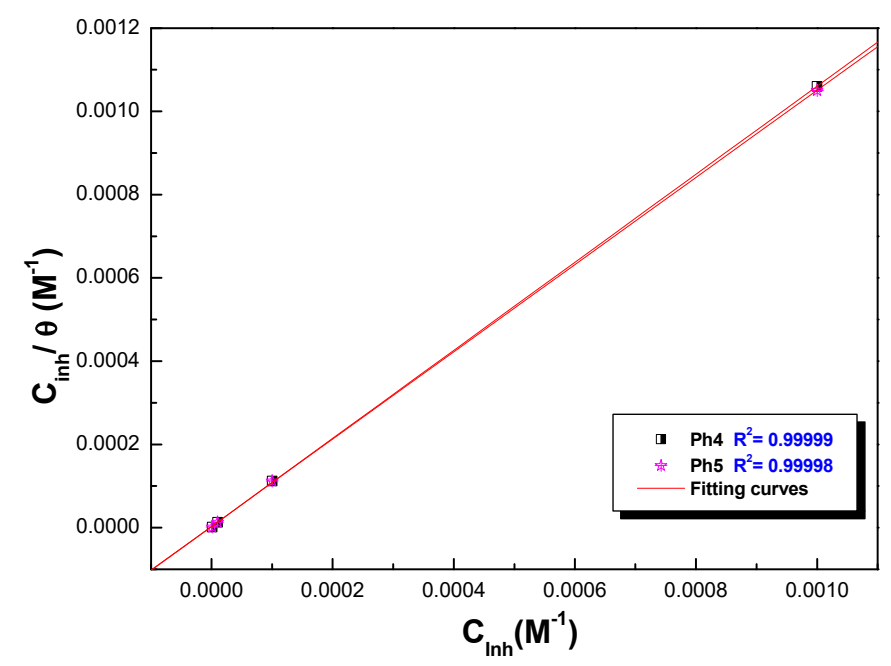

Figure 6. Langmuir isotherm for the mild steel in $1 \mathrm{M} \mathrm{HCl}$ with different concentrations of $\mathrm{Ph} 4$ and $\mathrm{Ph} 5$ at $298 \mathrm{~K}$.

As shown in Fig 4, the plot of $\mathrm{C} / \theta$ versus $\mathrm{C}$ gives rise to a linear correlation, and the free adsorption energy $\Delta \mathrm{G}^{*}$ has been estimated by Eq.(6):

$K=\frac{1}{55.5} \exp \left(-\frac{\Delta G_{a d s}^{0}}{R T}\right)$

\section{Table6}

Activation parameters for mild steel in $1 \mathrm{M} \mathrm{HCl}$ in the absence and in the presence of $\mathrm{Ph} 4$ and $\mathrm{Ph} 5$ at different concentrations

\begin{tabular}{ccc}
\hline Inhibitors & $\mathbf{K}$ & $\Delta \boldsymbol{G}_{\text {ads }}^{\mathbf{0}}\left(\mathbf{k J} . \mathbf{m o l}^{\mathbf{1}}\right)$ \\
\hline Ph4 & $3,38.10^{5}$ & $-41,5$ \\
\hline Ph5 & $2,98.10^{5}$ & $-41,1$ \\
\hline
\end{tabular}

The negative and low value of the free enthalpy of adsorption $\Delta G_{a d s}^{0}$ indicates that the inhibitor was adsorbed spontaneously at the surface of the mild steel. This type of isotherm is generally 
corresponding to chemisorption [43], implies the hypothesis of the absence of interactions between the species adsorbed on the surface of the electrode.

\subsection{Quantum chemical calculations}

In order to explain the experimental findings and to search possible correlation between experimentalresults and electronic properties of tested compounds, the quantum chemical calculations were calculated to give adsorption and inhibition mechanism of $\mathrm{Ph} 4$ and $\mathrm{Ph} 5$. The values of quantum chemical parameters were carried out by using DFT at B3LYP/6-31G $(\mathrm{d}, \mathrm{p})$. The optimized molecularstructure of $\mathrm{Ph} 4$ and $\mathrm{Ph} 5$ are presented in table 6 . 
Table 6

Optimized molecular structures of neutral compounds 1, 2 and 3 with HOMO and LUMO orbitals.

\section{Inhibitor}

Optimize molecular

\section{Structures}

Ph4
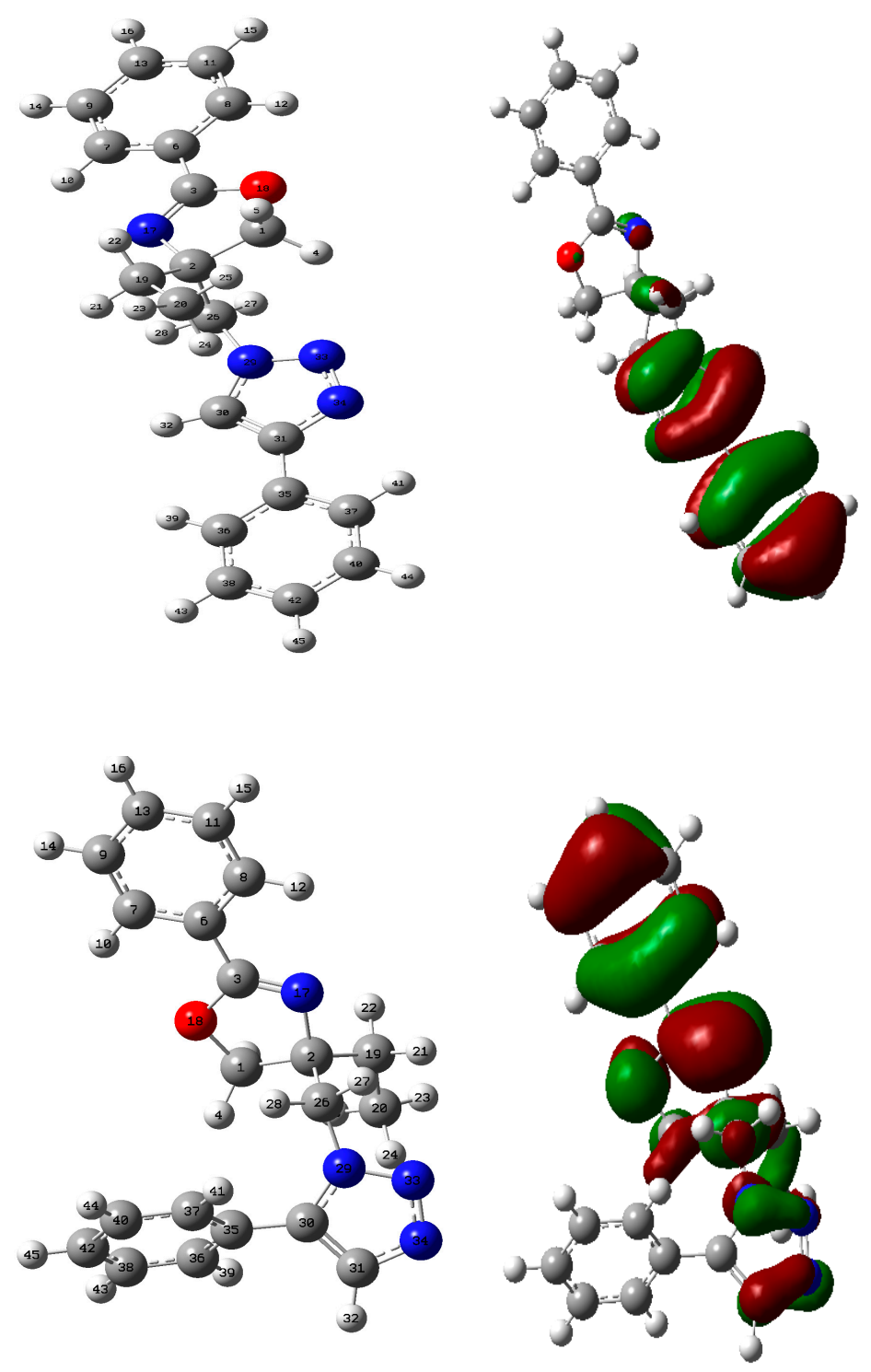

Ph5

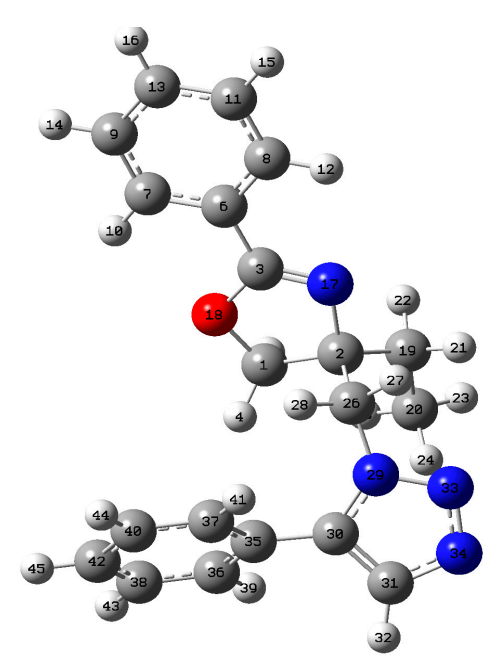

\section{LUMO}

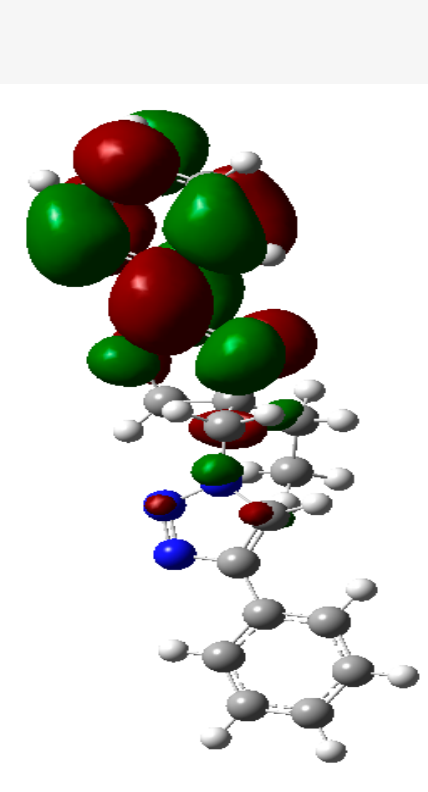

HOMO

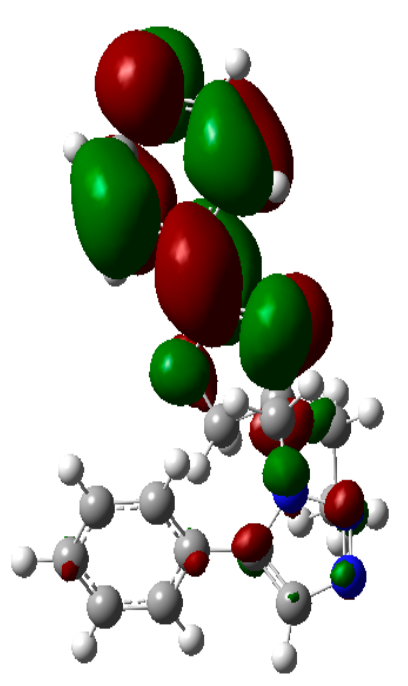

The total energy $(\Delta E)$, the ionization potential $(\mathrm{I})$, the electron-affinity $(A)$, the number of transferred electrons $(\Delta N)$ the electronegativity $(\chi)$ and the global hardness $(\eta)$ were calculated using Eq.(7) and listed in Table 7[44-45].

$$
\begin{gathered}
\mathbf{A}=\mathbf{-} \mathbf{E}_{\text {Lomo }} \quad ; \quad \mathbf{I}=-\mathbf{E}_{\text {HUMo }} \quad ; \quad \boldsymbol{\chi}=\frac{\mathbf{I}+\mathbf{A}}{\mathbf{2}} \quad ; \boldsymbol{\eta}=\frac{\mathbf{I}-\mathbf{A}}{\mathbf{2}} \\
\Delta \mathrm{N}=\frac{\chi_{F e}-\chi_{i n h}}{2\left(\eta_{F e}+\eta_{i n h}\right)} \Delta \mathrm{E}=\mathrm{E}_{\text {LUMо }}-\mathrm{E}_{\mathrm{Homo}} \quad \text { (7) }
\end{gathered}
$$


where Еномо is the Highest occupied molecular orbital energy and ELumo is the lowest unoccupied molecular orbital energy, $\chi_{\mathrm{Fe}}=7 \mathrm{ev}$ and $\chi_{\text {inh }}$ denote the absolute electronegativity of iron and inhibitor molecule, $\eta_{\mathrm{Fe}}=0 \mathrm{ev}$ and $\eta_{\text {inh }}$ denote the absolute hardness of iron and inhibitor molecule respectively [46-47].

Table 7.The calculated quantum chemical parameters of the investigated inhibitors

\begin{tabular}{ccccccccccc}
\hline \multirow{2}{*}{ Inhibitors } & Phase & $\begin{array}{c}\mathbf{E}_{\text {HOMо }} \\
(\mathbf{e v})\end{array}$ & $\begin{array}{c}\mathbf{E}_{\text {LUMO }} \\
(\mathbf{e v})\end{array}$ & $\begin{array}{c}\Delta \mathbf{E} \\
(\mathbf{e v})\end{array}$ & $\begin{array}{c}\boldsymbol{\mu} \\
\text { (D) }\end{array}$ & $\begin{array}{c}\mathbf{A} \\
(\mathbf{e v})\end{array}$ & $\begin{array}{c}\mathbf{I} \\
(\mathbf{e v})\end{array}$ & $\begin{array}{c}\boldsymbol{\eta} \\
(\mathbf{e v})\end{array}$ & $\begin{array}{c}\mathbf{X} \\
(\mathbf{e v})\end{array}$ & $\Delta \mathbf{N}$ \\
\hline \multirow{2}{*}{ Ph4 } & G & $-6,0302$ & $-1,1843$ & 4,8459 & 3,1211 & 1,1843 & 6,0302 & 2,4230 & 3,6073 & 0,7001 \\
& A & $-6,1855$ & $-1,2572$ & 4,9284 & 3,1211 & 1,2572 & 6,1855 & 2,4642 & 3,7214 & 0,6653 \\
\multirow{2}{*}{ Ph5 } & G & $-6,4901$ & $-1,1701$ & 5,3201 & 5,4507 & 1,1701 & 6,4902 & 2,6600 & 3,8302 & 0,5958 \\
& A & $-6,5976$ & $-1,2632$ & 5,3344 & 5,4507 & 1,2632 & 6,5976 & 2,6672 & 3,9304 & 0,5754 \\
\hline
\end{tabular}

The charge transfer rate $\Delta \mathrm{N}$ describes the electron donation tendency inside of a set of inhibitors. According to Lukovits [48], if $\Delta \mathrm{N}<3.6$ the effectiveness of the inhibition Increases with increasing electron donor capacity at the steel /electrolyte. The values obtained from $\Delta \mathrm{N}$ in the table 7 are all lower by 3.6. The difference between the energy levels HOMO and LUMO of the molecules, $\Delta \mathrm{E}=$ Elumo-Eномо, Is another important descriptor that must be considered [4950]. The energy gap called also the Gap describes the energy needed to perform the first excitation, so the efficiency of the inhibition of corrosion is inversely proportional to the value of the Gap. The results of our study in Table 6 showed that the number of transferred electrons $\Delta N$ obtained with $\mathrm{Ph} 4$ is higher than $\mathrm{Ph} 5$, which strongly respect the experimental study. In addition, the energy gap values follow the order $\Delta \mathbf{E}(\mathrm{Ph} 4)<\boldsymbol{\Delta} \mathbf{E}(\mathrm{Ph} 5)$ which is in accordance with the order of inhibition efficiency of our compounds EI\% $(\mathrm{Ph} 4)>\mathrm{EI} \%(\mathrm{Ph} 5)$.

\section{Conclusion}

- The triazole regioisomers had very good inhibition efficiency for the corrosion of mild steel in $1 \mathrm{M} \mathrm{HCl}$ and that their corrosion rate was delayed to an optimal concentration $10^{-3} \mathrm{M}$. The inhibition efficiency follows the order: $\mathrm{Ph} 4>\mathrm{Ph} 5$ which shows that substitution plays an important role in the inhibition efficiency.

- The adsorption of both $\mathrm{Ph} 4$ and $\mathrm{Ph} 5$ molecules onto surface of the mild steel in the $1 \mathrm{M} \mathrm{HCl}$ solutions gave a good fit to the Langmuir isotherm model.

- The polarizationmeasurements indicate that the both inhibitors are act as mixed type inhibitors.

- Inhibitory action isexplained by the chemical adsorption of $\mathrm{Ph} 4$ and $\mathrm{Ph} 5$ on the mild steel surface 
- EIS measurement results indicate that the resistance of the carbon steel electrode increases greatly and itscapacitance decreases by increasing the inhibitor concentration.

- The quantum chemical parameters show the efficiency obtained by gravimetric study, Tafel polarization, and the EIS method.

\section{References}

1. L. Xianghong, $\mathrm{X}$. Xiaoguang, Adsorption and inhibition effect of two aminopyrimidine derivatives on steel surface in $\mathrm{H}_{2} \mathrm{SO}_{4}$ solution, J TAIWAN INST CHEM E. 45 (2014) 3033-3045.

2. M. Behpou, S.M. Ghoreishi, N. Soltani, M. Salavati-Niasari, The inhibitive effect of some bis-N,Sbidentate Schiff bases on corrosion behaviour of 304 stainless steel in hydrochloric acid solution, Corr. Sci. 51 (2009) 1073-1082.

3. A. Bouoidina, F. El-Hajjaji, M. Chaouch, A. Abdellaoui, H. Elmsellem, Z. Rais, M. Filali Baba, A. Lahkimi, B. Hammouti, M. Taleb, Inhibition of mild steel corrosion using the extract of Foeniculum vulgare in acid medium, Der PharmaChemica.8 (2016) 149-157.

4. A. Ali. Sk, M.T. Saeed, S.U. Rahman. S.U., The isoxazolidines: a new class of corrosion inhibitors of mild steel in acidic medium, Corr. Sci..45 (2003) 253-266.

5. L. El Ouasif, I. Merimi, H. Zarrok, M. El Ghoul, R. Achour, M. Guenbour, H. Oudda, F. El-Hajjaji, B. Hammouti, Synthesis and inhibition study of carbon steel corrosion in hydrochloric acid of a new surfactant derived from 2-mercaptobenzimidazole. J.Mater. Env. Sci.7 (2016) 2718-2730.

6. G. Schmitt, Application of Inhibitors for Acid Media: Report prepared for the European Federation of Corrosion Working Party on Inhibitors Br. Corr. J.. 19 (1984)165- 176.

7. M. Lebrini, M. Traisnel, M. Lagrenee, B. Menari, F. Bentiss, Inhibitive properties, adsorption and a theoretical study of 3,5-bis(n-pyridyl)-4-amino-1,2,4-triazoles as corrosion inhibitors for mild steel in perchloric acid, Corr. Sci., 50 (2008) 473-479.

8. M.A. Quraishi, S. Ahmad, M.Q. Ansari., Inhibition of steel corrosion by some new triazole derivatives in boiling hydrochloric acid, Br. Corr. J..32 (1997) 297-300.

9. F. Bentiss, M. Lagrenee, M. Traisnel, J.L. Hornez, The corrosion inhibition of mild steel in acidic media by a new triazole derivative, Corr. Sci.. 41 (1999) 789-803.

10.K.R. Ansari, M.A. Quraishi, A. Singh, Schiff's base of pyridyl substituted triazoles as new and effective corrosion inhibitors for mild steel in hydrochloric acid solution, Corr. Sci. 79 (2014) 5-15.

11.P. Rugmini Ammal, M. Prajila, Abraham Joseph, Effective inhibition of mild steel corrosion in hydrochloric acid using EBIMOT, a 1, 3, 4-oxadiazole derivative bearing a 2-ethylbenzimidazole moiety: Electro analytical, computational and kinetic studies, Egyp. J. Petro.,in press (2017). https://doi.org/10.1016/j.ejpe.2017.12.004

12. Y.Aouine, A. El Hallaoui, A. Alami, N,N-Dibenzyl-1-(1-[(4-methyl-2-phenyl-4,5-dihydrooxazol-4yl)methyl)]-1H-1,2,3-triazol-4-yl)methanamine.Molbank, 2014, M 819. 
13.S. El Arrouji, K. Ismaily Alaoui, A. Zerrouki, S. EL Kadiri, R. Touzani, Z. Rais, M. Filali Baba, M. Taleb, A. Chetouani, A. Aouniti,The Influence of Some Pyrazole Derivatives on The Corrosion Behaviour of Mild Steel in 1M HCl Solution, J. Mater. Environ. Sci., 7 (1) (2016) 299-309.

14.K. I. Alaoui, F. Ouazzani, Y. kandrirodi, A.M. Azaroual, Z. Rais, M. Filali Baba, M. Taleb, A. Chetouani, A. Aouniti, B. Hammouti, Effect of some Benzimidazolone compounds on C38 steel corrosion in hydrochloric acid solution, J. Mater. Environ. Sci., 7 (1) (2016) 244-258

15.B. Zerga , A., Attayibat, M.Sfaira, M.Taleb, B.Hammouti, M.EbnTouhami, S.Radi, Z.Rais, Effect of some tripodal bipyrazolic compounds on C38 steel corrosion in hydrochloric acid solution, J. Appl. Electrochem., 40 (2010) 1575-1582.

16.Q. Deng, N. Ding, X-Li Wei, L. Cai, X-Peng He, Y-Tao Long, G-Rong Chen, K. Chen, Identification of diverse 1,2,3-triazole-connected benzyl glycoside-serine/threonine conjugates as potent corrosion inhibitors for mild steel in HCl, Corr. Sci., 64 (2012) 64-73

17.B. Zerga, A. Attayibat, M. Sfaira, M. Taleb, B. Hammouti, M. EbnTouhami, S. Radi, Z. Rais, Effect of some tripodal bipyrazolic compounds on C38 steel corrosion in hydrochloric acid solution, J. Appl. Electrochem., 40 (2010) 1575-1582

18.D. Ben Hmamou, R. Salghi, A. Zarrouk, H. Zarrok, M. Assouag, B. Hammouti, S.S. Al-Deyab, M. El Hezzat, Inhibition of carbon steel corrosion in phosphoric acid solution by Alizarin red, Der Pharma. Letter, 5 (2013) 135-142.

19.M. Chellouli, D. Chebabe, A. Dermaj, H. Erramlia, N. Bettach, N. Hajjaji, M.P. Casaletto, C. Cirrincion, A. Privitera, A. Srhiri, Corrosion inhibition of iron in acidic solution by a green formulation derived from Nigella sativa L., Electrochemica Acta, 204 (2016) 50-59.

20.M.J. Frisch, Gaussian 03, Revision B.01, Gaussian, Inc., Pittsburgh, PA, 2003.

21.Y. Kharbach, A. Haoudi, M.K. Skalli, Y. KandriRodi, A. Aouniti, B. Hammouti, O. Senhaji, A. Zarrouk, The role of new phosphonate derivatives on the corrosion inhibition of mild steel in $1 \mathrm{M}$ H2SO4 media, J. Mater. Environ. Sci., 6 (2015) 2906-2916.

22.K. Benbouya, B. Zerga, M. Sfaira, M. Taleb, M. EbnTouhami, B. Hammouti, H. Benzeid, E.M. Essassi. WL, I-E and EIS Studies on the Corrosion Behaviour of Mild Steel by 7-substituted 3methylquinoxalin-2(1H)-ones and thiones in Hydrochloric Acid Medium, Int. J. Electroch. Sci., 7 (2012) $6313-6330$.

23.B. Zerga, R. Saddik, B. Hammouti, M. Taleb, M. Sfaira, M. EbnTouhami, S.S. Al-Deyab, N. Benchat, Synthesis and Electropolymerization of 1,4-Bis(2-Thienyl)-2,5-Difluorobenzene and its Electrochromic Properties and Electrochromic Device Application , Int. J. Electrochem. Sci., 7 (2012) 615-630.

24.E.S. Ferreira, C. Giancomelli, F.C. Giacomelli, A. Spinelli, Evaluation of the Inhibitor Effect of LAscorbic Acid on the Corrosion of Mild Steel, Mater.Chem. Phy., 83 (2004) 129-134.

25.A.A., Farag, M.A. Hegazy, Synergistic inhibition effect of potassium iodide and novel Schiff bases on X65 steel corrosion in $0.5 \mathrm{M} \mathrm{H}_{2} \mathrm{SO}_{4}$, Corros. Sci. 74 (2013) 168-177. 
26.E. Ech-chihbi, M.E. Belghiti, R. Salim, H. Oudda, M. Taleb, N. Benchat, B. Hammouti, F. El-Hajjaji, Experimental and computational studies on the inhibition performance of the organic compound "2-phenylimidazo [1,2-a]pyrimidine-3-carbaldehyde" against the corrosion of carbon steel in 1.0M HCl solution, Surfaces and Interfaces, 9 (2017) 206-217.

27. Q. Zhao 1, T. Tang, P. Dang, Z. Zhang, F. Wang, The Corrosion Inhibition Effect of Triazinedithiol Inhibitors for Aluminum Alloy in a 1 M HCl Solution, Metals, 7 (2017) 44.

28.P. Mourya, S. Banerjee, M. Singh, Corrosion inhibition of mild steel in acidic solution by Tagetes erecta (Marigold flower) extract as a green inhibitor, Corr. Sci., 85 (2014) 352-363.

29.S. Abd El-Meksoud, A. El-Desoky, A. El-Sonbati, A. Belal, R. El-Boz, Determination of the Thermodynamic Parameters, Characterizing the Adsorption and Inhibitive Properties of some 3-phenyl2-thioxo- 4-thiazolidinone Derivatives, IJSER, 4 (2013) 1986-1994.

30.T. Tsuru, S. Haruyama, B. Gijutsu, Corrosion Inhibition of Iron by Amphoteric Surfactants in 2M HCl, J.Jap. Soc. Corr. Eng., 27 (1978) 573-581.

31.M.G. Sethuraman, P. Bothi Raja, Corrosion inhibition of mild steel by Datura metel in acidic medium, Pigment \& Resin Technology, 34 (2005) 327-331.

32.H.Wang, R.Liu, J. Xin, Inhibiting effects of some mercapto-triazole derivatives on the corrosion of mild steel in 1.0 M HCl medium, Corr. Sci., 46 (2004) 2455-2466.

33.I. Forsal, L. Lakhrissi , K. Naji , S. Abirou, M. EbnTouhami, B. Lakhrissi, M. Addou, The Efficiency of Corrosion Inhibitor as Given by Electrochemical Impedance Spectroscopy Tafel Polarization and Weight-Loss Measurements, Spectroscopy Letters. 43 (2010) 136-143.

34.F. Bentiss, M .Lagrence, M .Traisnel, 2,5-Bis(n-Pyridyl)-1,3,4-Oxadiazoles as Corrosion Inhibitors for Mild Steel in Acidic Media Corrosion, 56 (2000) 733-742.

35.A. Popova, E. Sokolova, S. Raicheva, M. Christov, AC and DC study of the temperature effect on mild steel corrosion in acid media in the presence of benzimidazole derivatives, Corrosion Science. 45 (2003) 33-58.

36.M. Ozcan, I. Dehri, M. Erbil, Organic sulphur-containing compounds as corrosion inhibitors for mild steel in acidic media: correlation between inhibition efficiency and chemical structure, Appl.Sur. Sci., 236 (2004) 155-164.

37.K. Tebbji, N. Faska, A. Tounsi, H. Oudda, M. Benkaddour and B. Hammouti. The Effect of Some Lactones as Inhibitors for the Corrosion of Mild Steel in 1 M Hydrochloric Acid, Mater. Chem. Phy., 106 (2007) 260-267.

38.J.O.M. Bochris, A.K.N. Reddy, Modern Electrochemistry, Plenum Press, New York, 1977, $2,1267$.

39.S.A. Ali, A.M. El-Shareef, R.F. Al-Ghamdi, The isoxazolidines: the effects of steric factor and hydrophobic chain length on the corrosioninhibition of mild steel in acidic medium, Corr. Sci., 47 (2005) 2659.

40.G.K. Gomma, M.H. Wahdan, Schiff bases as corrosion inhibitors for aluminium in hydrochloric acid solution. Mater. Chem. Phy., 39 (1995) 209. 
41.L. Afia, H. Lgaz, M. Zougagh, M. Belkhaouda, S. Jodeh, M. Algarra, Kaempferol as a corrosion inhibitor on mild steel in $\mathrm{HCl}$, Appl. J. Envir. En. Sci. 2 N²(2016) 42-55

42.Y. EL Aoufir, H. Lgaz, H. Bourazmi, Y. Kerroum, Y. Ramli, A. Guenbour, R. Salghi, F. El-Hajjaji, B. Hammouti, H. Oudda, Quinoxaline Derivatives as Corrosion Inhibitors of Carbon Steel in Hydrochloridric Acid Media: Electrochemical, DFT and Monte Carlo simulations studies , J. Mater. Environ. Sci. 7 (12) (2016) 4330-4347

43.D. Qiong, D. Na-Na, W. X. Li, C. Liang, P. X. He, Longa. Y.Tao, K. G.R. Chen. Academy of Sciences, Shanghai 201203, PR China.

44.B. Zerga, B. Hammouti, M. EbnTouhami, R. Touir, M. Taleb, M. Sfaira, M. Bennajeh, I. Forssal, Comparative Inhibition Study of New Synthesised Pyridazine Derivatives Towards Mild Steel Corrosion in Hydrochloric Acid., Int. J. Electrochem. Sci.,7 (2012) 471-483.

45.A. Ghazoui, N. Benchat, F. El-Hajjaji, M. Taleb, Z. Rais, R. Saddik, A. Elaatiaoui, B. Hammouti, The study of the effect of ethyl (6-methyl-3-oxopyridazin-2-yl) acetate on mild steel corrosion in $1 \mathrm{M} \mathrm{HCl,} \mathrm{J.}$ Alloys Compd, 693 (2017) 510-517.

46.R.S. Oguike R.S., A.M. Kolo, A.M. Shibdawa, H.A. Gyenna, Density functional theory of mild steel. corrosion in acidic media using dyes as. inhibitor: Adsorption onto Fe(110) from gas. phaseISRN Phys. Chem., 175910 (2013) 1-9.

47.H. El Sayed, El Ashry, A. El Nemr, S. Ragab, Quantitative structure activity relationships of some pyridine derivatives as corrosion inhibitors of steel in acidic medium, J. Mol. Model., 18 (2012) 11731188.

48.I. Lukovits, E. Kalman, F. Zucchi, Corrosion Inhibitors Correlation between Electronic Structure and Efficiency, Corrosion, 57 (2001) 3-8.

49.F. El-Hajjaji, R.A. Belkhmima, B. Zerga, M. Sfaira, M. Taleb, M. EbnTouhami, B. Hammouti, S.S. AlDeyab, E. Ebenso., Temperature performance of a thione quinoxaline compound as mild steel corrosion inhibitor in hydrochloric acid medium, Int. J. Electrochem. Sci., 9(2014) 4721-4731.

50.N. Khalil, Quantum chemical approach of corrosion inhibition, Electrochim. Acta, 48 (2003) 26352640. 